\title{
PROFIL KOMPONEN FISIK PREDOMINAN DARI KONDISI FISIK ATLET GULAT JAWA BARAT PADA PON XVIII RIAU 2012
}

\author{
Karima Akhlaqunnisa ${ }^{1}$, Titing Nurhayati ${ }^{2}$, Nova Sylviana ${ }^{2}$, Ambrosius Purba ${ }^{2}$, Panji Fortuna Hadisoemarto ${ }^{3}$ \\ ${ }^{1}$ Fakultas Kedokteran, Universitas Padjadjaran, Bandung, Indonesia, \\ ${ }^{2}$ Departemen Anatomi, Fisilogi, dan Biologi Sel, Fakultas Kedokteran, Universitas Padjadjaran, Bandung, Indonesia, \\ ${ }^{3}$ Departemen Ilmu Kesehatan Masyarakat, Fakultas Kedokteran, Universitas Padjadjaran, Bandung, Indonesia.
}

\begin{abstract}
During the National Sports Week XVIII held in September 2012, wrestling athletes from West Java Province could not meet the expected performance; since they got only one gold and two bronze medals. The athlete's performance usually affected by three factors; physical condition, technique, and mental condition. To achieve the best result, the gold medal, athletes should have good predominant physical condition indicators, such as muscle strength, endurance, power, and flexibility. The purpose of this study is to know the physical condition of West Java's wrestling athletes in the National Sports Week XVIII. The method used was cross-sectional descriptive study using secondary data obtained from Sports Medicine Department of National Sports Committee of Indonesia in Bandung. The data are chosen from predominant physical condition indicator explained before, along with cardio-respiratory endurance. After that, we compared the data we obtained with National Sports Committee of Indonesia's standards and categorized it specific type; less, enough, good, very good, and perfect. Male and female athletes had different category system. After analyzed, we found that several predominant physical components of wrestling athletes of West Java Province in National Sports Week XVIII had not met the requirement for good and perfect category and needed to be improved. In conclusion, athletes should be able to get a gold medal if their predominant physical component achieves the good and perfect category.
\end{abstract}

Keywords: a physical component of wrestling athletes, physical predominant component

Korespondensi: Karima Akhlaqunnisa, E-mail: akhlaqunnisakarima@yahoo.com, Departemen Anatomi, Fisiologi, dan Biologi Sel, Fakultas Kedokteran Universitas Padjadjaran. Jalan Raya Jatinangor Km 21, Sumedang, Jawa Barat, Indonesia. 


\section{PENDAHULUAN}

Gulat merupakan salah satu cabang olahraga dengan event kejuaraan di tingkat lokal, nasional, regional maupun dunia. ${ }^{1,2,3}$ Atlet gulat Indonesia belum pernah meraih prestasi di Olimpiade. Akan tetapi, pada kejuaraan SEA Games atlet gulat Indonesia memperoleh medali 2 emas, 4 perak, dan 6 perunggu pada tahun 2009. ${ }^{4}$ Pada tahun 2011, Indonesia memperoleh 4 emas, 5 perak, dan 3 perunggu. ${ }^{5}$ Akan tetapi, pada tahun 2013 mengalami penurunan yaitu mendapatkan 2 emas, 5 perak, dan 3 perunggu. $^{6}$

Prestasi puncak seorang atlet dapat diraih pada atlet yang menjalani proses pelatihan yang berjenjang dan berkelanjutan. Terdapat tiga faktor utama agar atlet dapat meraih prestasi yang maksimal, yaitu kondisi fisik atlet, teknik atau strategi serta kesiapan mental atlet. $^{7}$ Kemampuan atletik yang sempurna, latihan jangka panjang yang progresif, dan performa yang baik saat pertandingan dibutuhkan oleh seorang atlet agar dapat mendapatkan medali emas dalam kejuaraan nasional maupun internasional. ${ }^{8}$

Atlet gulat Jawa Barat harus memiliki kondisi fisik yang baik agar dapat tampil dengan sukses di kompetisi nasional maupun internasional. Masih sedikitnya medali yang didapatkan oleh atlet gulat Jawa Barat kemungkinan karena kondisi fisik atlet gulat Jawa Barat tidak sesuai dengan standar KONI pusat. $^{8}$ Penelitian ini dilakukan untuk mengetahui profil komponen fisik predominan dari kondisi fisik atlet gulat PON XVIII Jawa Barat.

\section{METODE}

Penelitian dilakukan dari bulan September 2016 - Juni 2017 dengan menggunakan data sekunder hasil pengukuran komponen fisik predominan dari kondisi fisik atlet gulat PON XVIII Jawa Barat yang dilakukan oleh bidang Sport Medicine Komite Olahraga Nasional Indonesia, Jawa Barat. Subjek penelitian adalah data kebugaran fisik atlet gulat PON XVIII Jawa Barat dengan kriteria inklusi berupa data komponen fisik predominan dari kondisi fisik yang terdiri dari kekuatan, daya tahan otot, power, kelentukan, dan daya tahan jantung - paru yang lengkap. Total subjek penelitian ini adalah sepuluh atlet gulat yang dipersiapkan untuk PON XVIII, 2012 yang terdiri dari delapan laki-laki dan dua perempuan.

Data primer komponen fisik predominan dari kondisi fisik atlet gulat diambil menggunakan alat ukur berupa Astrand test untuk mengukur daya tahan jantung - paru; leg dynamometer untuk mengukur kekuatan otot tungkai; sit- ups untuk mengukur daya tahan otot perut, pull- ups untuk mengukur daya tahan otot lengan dan bahu, dan squat jumps untuk mengukur daya tahan otot tungkai; medicine ball put untuk mengukur power otot lengan, vertical jump untuk mengukur power otot tungkai; dan flexometer untuk mengukur kelentukan.

Hasil pengukuran tersebut kemudian dibandingkan dengan standar KONI Pusat sebagaimana dicantumkan pada tabel 1. Standar komponen fisik atlet gulat KONI Pusat adalah kemampuan komponen fisik atlet - atlet gulat yang meraih medali emas pada kejuaraan tingkat Asia maupun kejuaraan Internasional lainnya.

\section{HASIL}

Jumlah sampel pada penelitian ini adalah sepuluh atlet gulat PON XVIII Jawa Barat. Berdasarkan Tabel 2, rata- rata usia atlet gulat PON XVIII Jawa Barat adalah 22,8 tahun ( $\mathrm{SD}=2,6$ tahun) dengan rata- rata tinggi badan yaitu $164,5 \mathrm{~cm}$ $(\mathrm{SD}=8,3 \mathrm{~cm})$ dan rata- rata berat badan adalah 68,1 $\mathrm{kg}(\mathrm{SD}=14,9 \mathrm{~kg})$.

Tabel 3 menunjukkan bahwa masih ada beberapa komponen fisik predominan atlet gulat putera PON XVIII Jawa Barat yang termasuk kategori kurang dan cukup, yaitu daya tahan otot lengan dan bahu termasuk kategori cukup, daya tahan otot perut termasuk kategori cukup, dan daya tahan jantung- paru termasuk kategori cukup.

Tabel 4 menunjukkan bahwa masih ada beberapa komponen fisik predominan atlet gulat puteri PON XVIII Jawa Barat yang termasuk kategori kurang dan cukup, yaitu kekuatan otot tungkai termasuk kategori cukup, daya tahan otot perut termasuk kategori cukup, power otot tungkai kategori kurang, dan daya tahan jantung- paru termasuk kategori cukup.

Berdasarkan Tabel 3 dan Tabel 4 dapat digambarkan bahwa kemampuan komponen fisik predominan atlet gulat PON XVIII Jawa Barat tidak merata, oleh karena itu diperlukan pelatihan khusus untuk terhadap atlet untuk meningkatkan kemampuan fisik predominan tersebut agar lebih baik.

Berdasarkan Gambar 1, kekuatan otot tungkai atlet gulat PON XVIII Jawa Barat berada pada kategori baik (60\%), daya tahan otot perut atlet gulat berada pada kategori cukup $(60 \%)$, daya tahan otot lengan dan bahu atlet berada pada kategori cukup $(50 \%)$, daya tahan otot tungkai atlet berada pada kategori baik sekali dan sempurna (40\%), power otot lengan atlet berada pada kategori baik sekali (50\%), power otot tungkai atlet berada pada kategori baik (40\%), kelentukan atlet berada pada kategori baik dan sempurna (40\%), dan daya tahan 
jantung paru atlet berada pada kategori kurang $(50 \%)$.

Pada atlet gulat putera, komponen daya tahan otot lengan dan bahu termasuk kategori cukup, $(50 \%)$ daya tahan otot perut termasuk kategori cukup $(62,5 \%)$, dan daya tahan jantung - paru termasuk kategori cukup (50\%).
Pada atlet gulat puteri, kekuatan otot tungkai termasuk kategori cukup (50\%), daya tahan otot perut termasuk kategori cukup (50\%), power otot tungkai kategori kurang $(50 \%)$, dan daya tahan jantung- paru termasuk kategori cukup (50\%).

Tabel 1. Kategori Kemampuan Komponen Fisik Predominan (Komponen Fisik Dasar) dan Teknik Pengukuran Cabang Olahraga Gulat Standar KONI Pusat

\begin{tabular}{|c|c|c|c|c|c|c|c|c|}
\hline \multirow[b]{2}{*}{ No } & \multirow[b]{2}{*}{ Komponen } & \multirow[b]{2}{*}{ Satuan } & \multirow[b]{2}{*}{$\begin{array}{c}\text { Tingkat } \\
\text { Pengukuran }\end{array}$} & \multicolumn{5}{|c|}{ Kategori } \\
\hline & & & & Kurang & Cukup & Baik & $\begin{array}{c}\text { Baik } \\
\text { Sekali }\end{array}$ & Sempurna \\
\hline \multirow[t]{4}{*}{1} & Kekuatan & & & & & & & \\
\hline & Otot Punggung & $\mathrm{kg}$ & $\begin{array}{l}\text { Back } \\
\text { Dynamometer }\end{array}$ & $59-79.5$ & $\begin{array}{r}80- \\
100.6\end{array}$ & $\begin{array}{r}101- \\
122\end{array}$ & $\begin{array}{r}122.5- \\
143\end{array}$ & $\geq 144$ \\
\hline & Otot Tungkai & $\mathrm{kg}$ & $\begin{array}{l}\text { Leg } \\
\text { Dynamometer }\end{array}$ & $77-145$ & $\begin{array}{r}146- \\
214\end{array}$ & $\begin{array}{r}215- \\
282\end{array}$ & $\geq 283$ & \\
\hline & Otot Lengan dan Bahu & $\mathrm{kg}$ & $\begin{array}{l}\text { Hand } \\
\text { Dynamometer }\end{array}$ & $23-29$ & $30-36$ & $37-43$ & $44-52$ & $\geq 51$ \\
\hline \multirow[t]{4}{*}{2} & Daya Tahan Otot & & & & & & & \\
\hline & Otot perut & kali & Sit ups & $10-20$ & $21-31$ & $32-42$ & $43-53$ & $\geq 54$ \\
\hline & $\begin{array}{l}\text { Otot Lengan dan } \\
\text { Bahu }\end{array}$ & kali & Pull ups & $0-6$ & $7-13$ & $14-20$ & $21-27$ & $\geq 28$ \\
\hline & Otot Tungkai & kali & Squat Jumps & $4-12$ & $25-45$ & $46-66$ & $67-87$ & $\geq 88$ \\
\hline \multirow[t]{3}{*}{3} & Power & & & & & & & \\
\hline & Otot Lengan & $\mathrm{cm}$ & $\begin{array}{l}\text { Medicine ball } \\
\text { put }\end{array}$ & $\begin{array}{r}2.63- \\
3.67\end{array}$ & $\begin{array}{r}3.68- \\
4.52\end{array}$ & $\begin{array}{r}4.53- \\
5.37\end{array}$ & $\begin{array}{r}5.38- \\
6.22\end{array}$ & $\geq 6.23$ \\
\hline & Otot Tungkai & $\mathrm{cm}$ & Vertical Jump & $38-45$ & $46-52$ & $53-61$ & $62-69$ & $\geq 70$ \\
\hline 4 & Kelentukan & $\mathrm{cm}$ & Flexometer & $1-5$ & $6-11$ & $12-17$ & $18-23$ & $\geq 24$ \\
\hline 5 & $\begin{array}{l}\text { Daya Tahan Umum } \\
\text { (Kardiovaskular) }\end{array}$ & $\mathrm{ml} / \mathrm{kg} / \mathrm{mnt}$ & $\begin{array}{l}\text { Astrand }\left(\mathrm{VO}_{2}\right. \\
\max )\end{array}$ & $\leq 36$ & $37-45$ & $46-54$ & $55-67$ & $\geq 68$ \\
\hline
\end{tabular}

\section{Sebaran Kualitas Komponen Fisik Predominan Atlet Gulat PON XVIII Jawa Barat Berdasarkan Standar KONI Pusat}

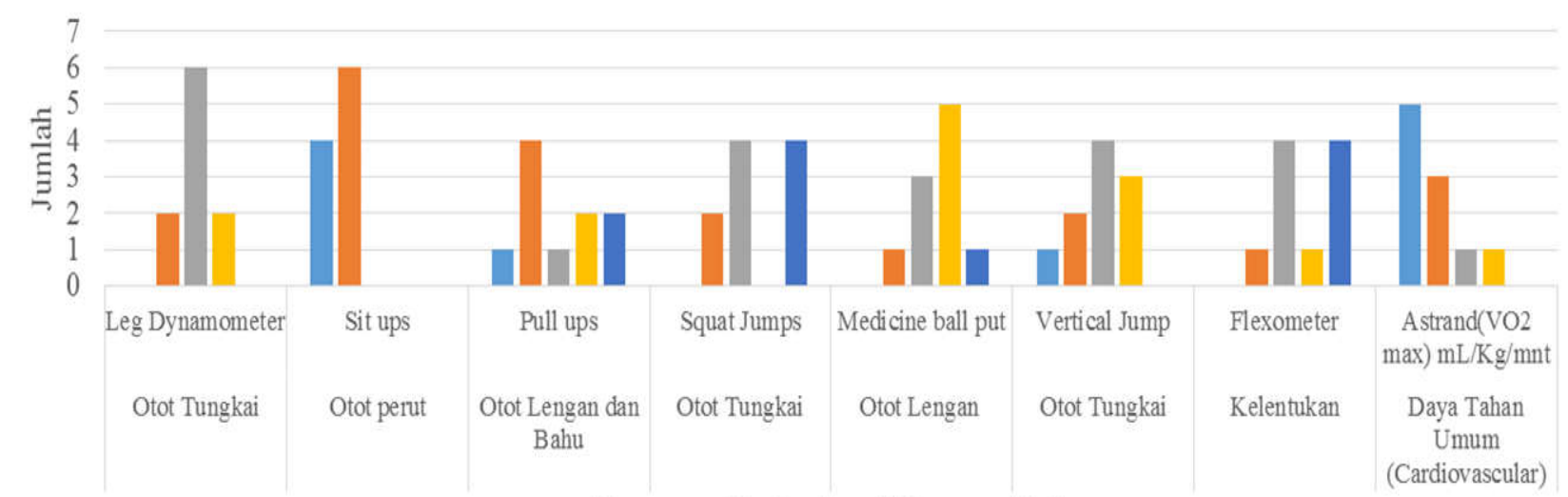

Komponen Predominan Kebugaran Fisik

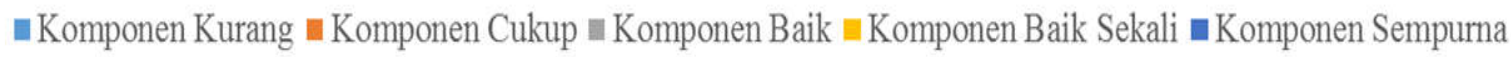

Gambar 1. Persebaran Kategori Komponen Kondisi Fisik Predominan dari Kondisi Fisik Atlet Gulat PON XVIII Jawa Barat Berdasarkan Standar KONI Pusat 
Tabel 2. Karakteristik Umum Atlet Gulat PON XVIII Jawa Barat

\begin{tabular}{lcr}
\hline Karakteristik & \multicolumn{1}{c}{ Putra } & \multicolumn{2}{c}{ Putri } \\
& Rata- rata (SD) & Rata- rata (SD) \\
\hline Usia (tahun) & $22,7(2,7)$ & $23(2,8)$ \\
Berat badan $(\mathrm{kg})$ & $70,8(15,7)$ & $57,3(1,6)$ \\
Tinggi badan $(\mathrm{cm})$ & $167,2(6,7)$ & $153,5(0,7)$ \\
\hline
\end{tabular}

Tabel 3. Karakteristik Komponen Fisik Predominan dari Kondisi Fisik Atlet Gulat Putra PON XVIII Jawa Barat Berdasarkan Standar KONI Pusat

\begin{tabular}{lr}
\hline Karakteristik & $\begin{array}{c}\text { Rata }- \text { rata } \\
\text { (SD) }\end{array}$ \\
\hline Kekuatan otot & \\
$\quad$ Otot Tungkai (kg) & $245,1(38,4)$ \\
Daya tahan otot & \\
$\quad$ Otot lengan dan bahu (kali/menit) & $13,5(7,2)$ \\
$\quad$ Otot perut (kali/menit) & $20,3(8,8)$ \\
$\quad$ Otot Tungkai (kali/menit) & $79,3(29,8)$ \\
Power & \\
$\quad$ Otot lengan (cm) & $5,4(0,5)$ \\
$\quad$ Otot tungkai $(\mathrm{cm})$ & $58,5(6,7)$ \\
Kelentukan $(\mathbf{c m})$ & $17,9(5,9)$ \\
Daya tahan jantung - paru (ml/kg/menit) & $37,9(7,3)$ \\
\hline
\end{tabular}

Tabel 4. Karakteristik Komponen Fisik Predominan dari Kondisi Fisik Atlet Gulat Putri PON XVIII Jawa Barat Berdasarkan Standar KONI Pusat

\begin{tabular}{lr}
\hline Karakteristik & Rata - rata (SD) \\
\hline Kekuatan otot & \\
$\quad$ Otot Tungkai (kg) & $207,5(17)$ \\
Daya tahan otot & \\
Otot lengan dan bahu (kali/menit) & $38(2,8)$ \\
Otot perut (kali/menit) & $24,5(9,2)$ \\
Otot Tungkai (kali/menit) & $79,3(29,8)$ \\
Power & \\
Otot lengan (cm) & $4,9(1,5)$ \\
otot tungkai (cm) & $44,5(2,1)$ \\
Kelentukan (cm) & $23,1(11,8)$ \\
Daya tahan jantung - paru (ml/kg/menit) & $45,5(16,3)$ \\
\hline
\end{tabular}

\section{DISKUSI}

Penelitian ini bertujuan untuk mengetahui profil komponen fisik predominan dari kondisi fisik atlet gulat PON XVIII Jawa Barat berdasarkan standar KONI Pusat. Pada penelitian ini, masih ada beberapa komponen fisik predominan dalam kategori cukup dan kurang.

Pada penelitian ini didapatkan bahwa komponen fisik predominan atlet gulat putera PON XVIII Jawa Barat yaitu daya tahan jantung - paru termasuk kategori cukup dengan rata - rata 39,4 $\mathrm{ml} / \mathrm{kg} / \mathrm{menit}$. Hasil pengukuran ini masih lebih rendah dibandingkan dengan penelitian yang dilakukan oleh He Zi-Hong (2013) dan Yoon (2002) yang menyatakan atlet gulat yang dapat meraih medali emas atau dapat mengikuti perlombaan internasional memiliki nilai rata -rata $\mathrm{VO} 2$ max sebesar $50,58 \pm 3,33 \mathrm{ml} / \mathrm{kg} /$ menit. $^{2,3,10,11}$ Begitu juga dengan atlet gulat puteri PON XVIII Jawa Barat untuk komponen daya tahan jantung-paru termasuk kategori cukup dengan rata- rata 45,5 ml/kg/menit. Hasil pengukuran ini masih lebih rendah jika 
dibandingkan dengan penelitian yang dilakukan sebelumnya dengan rata- rata $51,28 \pm$ $1,821 / \mathrm{kg} /$ menit. $^{10}$

Daya tahan otot perut atlet gulat putera PON XVIII Jawa Barat termasuk kategori cukup dengan rata - rata 21,1 kali/menit. Hasil pengukuran ini jauh lebih rendah jika dibandingkan dengan penelitian yang dilakukan oleh Mirzaei (2011) yang menyatakan bahwa atlet gulat yang dapat meraih medali emas memiliki rata - rata $77 \mathrm{kali} /$ menit. $^{12}$ sama halnya dengan atlet gulat puteri untuk komponen daya tahan otot perut termasuk kategori cukup dengan rata - rata 24,5 kali/menit.

Sedangkan, untuk power otot tungkai atlet gulat putera PON XVIII Jawa Barat termasuk kategori baik dengan rata - rata $55,7 \mathrm{~cm}$. Hasil pengukuran ini sesuai dengan penelitian yang dilakukan oleh McGuigan (2006) yang menyatakan bahwa atlet gulat yang dapat berprestasi memiliki nilai $45 \mathrm{~cm}^{13}$

Daya tahan otot lengan dan bahu atlet gulat putera PON XVIII Jawa Barat termasuk kategori cukup dengan rata-rata $13,5 \mathrm{kali} /$ menit. Sedangkan, pada atlet gulat puteri PON XVIII Jawa Barat komponen kekukatan otot tungkai termasuk kategori cukup dengan rata- rata 207,5 kali/menit dan untuk komponen power otot tungkai termasuk kategori kurang dengan rata- rata $44,5 \mathrm{~cm}$.

Pada atlet gulat puteri PON XVIII Jawa Barat terdapat empat komponen fisik predominan yang belum mencapai kategori baik hingga sempurna, yaitu kekuatan otot tungkai, daya tahan otot perut, power otot tungkai, dan daya tahan jantung paru. Sedangkan, atlet gulat putera PON XVIII Jawa Barat memiliki tiga komponen fisik predominan yang belum mencapai kategori baik hingga sempurna, yaitu daya tahan otot lengan dan bahu, daya tahan otot perut, dan daya tahan jantungparu.
Berdasarkan penjelasan tersebut, kemungkinan yang menjadi salah satu faktor belum berprestasinya atlet gulat PON XVIII Jawa Barat karena masih ada beberapa komponen fisik predominan yang belum baik dan atau sempurna.

Hal ini dapat dijadikan acuan untuk proses seleksi atlet gulat Jawa Barat selanjutnya dan sebagai pedoman bagi pelatih gulat agar dapat meningkatkan kemampuan kondisi fisik atlet gulat Jawa Barat. Program latihan yang baik dapat membantu meningkatkan kondisi fisik seorang atlet sehingga dapat tampil dengan baik saat pertandingan. ${ }^{14}$ Selain itu, prestasi seorang atlet tidak hanya ditentukan oleh kondisi fisik, tetapi juga oleh teknik atau strategi atlet dan kesiapan mental atlet. ${ }^{8}$

Keterbatasan penelitian ini adalah peneliti hanya meneliti salah satu faktor yang mempengaruhi prestasi seorang atlet, yaitu kondisi fisik. Peneliti tidak meneliti faktor lain berupa strategi dan mental atlet gulat PON XVIII Jawa Barat karena waktu penelitian yang terbatas dan data sekunder yang terbatas.

\section{KESIMPULAN}

Dari penelitian ini dapat disimpulkan bahwa masih ada beberapa komponen fisik predominan dari kondisi fisik atlet gulat PON XVIII Jawa Barat yang belum mencapai kategori baik bahkan sempurna, sehingga diperlukan upaya untuk meningkatkan komponen fisik predominan atlet gulat Jawa Barat di masa yang akan datang melalui latihan yang terukur dan terprogram dengan baik. Penelitian selanjutnya diharapkan dapat mengambil jumlah sampel yang lebih banyak agar dapat memberikan gambaran yang lebih baik serta mempertimbangkan faktor lain selain aktivitas fisik yang dapat mempengaruhi prestasi seorang atlet yaitu strategi dan kesiapan mental atlet. 


\section{DAFTAR PUSTAKA}

1. Mirzaei B, Nezhad AA. A Skill Profile of Elite Iranian Greco-roman Wrestlers. World J Sport Sci. 2008;1(1):8-11.

2. García-Pallarés J, María López-Gullón J, Muriel X, Díaz A, Izquierdo M. Physical fitness factors to predict male Olympic wrestling performance. Eur J Appl Physiol. 2011;111(8):1747-58.

3. Ramirez-velez R, Argothyd R, Menesesechavez JF, Sanchez-puccini B, Lopez-alban CA, Cohen DD. Anthropometric Characteristics and Physical Performance of Colombian Elite Male Wrestlers. Asian J Sport Med. 2014;5(4):2-5.

4. Olympic Council of Asia. Overall Medal Standings - Indonesia 2009. [Diakses pada tanggal 1 April 2013]. Tersedia dari: http://www.ocasia.org/game/MWinner.aspx?Cn tbEpEabMRwnsc3yTf5WvIeXT1sBvVt.

5. Olympic Council of Asia. Overall Medal Standings - Indonesia 2011. [Diakses pada tanggal 1 April 2013]. Tersedia dari: http://www.ocasia.org/game/MWinner.aspx?Cn tbEpEabMRwnsc3yTf5WvIeXT1sBvVt.

6. Olympic Council of Asia. Overall Medal Standings - Indonesia 2013. [Diakses pada tanggal 1 April 2013]. Tersedia dari: http://www.ocasia.org/game/MWinner.aspx?Cn tbEpEabMRwnsc3yTf5WvIeXT1sBvVt.
7. Purba, 2012. Prestasi Puncak Atlet Tercapai dengan Menerapkan Iptek Olahraga, Khususnya Ilmu Faal Olahraga. [Diakses pada tanggal 12 Desember 2012]. Tersedia dari: http://www.unpad.ac.id/ profil/prof-drambrosius-purba-dr-m-sc-aifo-jika-inginberprestasi-iptek-olah-raga-harus-betul-betulditerapkan/

8. Tønnessen E, Sylta $\varnothing$, Haugen TA, Hem E, Svendsen IS, Seiler S. The Road to Gold: Training and Peaking Characteristics in the Year Prior to a Gold Medal Endurance Performance. PLoS One. 2014;9(7):15-7.

9. Hong HZ, Shi FL, Yi LM, Lucia A, Fleck SJ. Physiological Profile of Elite Chinese Female Wrestlers. J Strength Cond Res. 2013;27(9):2374-95.

10. Yoon J. Physiological profiles of elite senior wrestlers. Sports Med. 2002;32(2002):225-33.

11. Mirzaei B, Dg C, Barbas I, Lotfi N. Anthropometric and physical fitness traits of four-time World Greco-Roman wrestling champion in relation to national norms : A case study. J Hum Sport Exerc. 2011;6(2):406-13.

12. Mcguigan MR, Winchester JB, Erickson T. The Importance Of Isometric Maximum Strength In College Wrestlers. J Sport Sci Med. 2006;10813.

13. Barbas I. The relationship between flexibility, speed and agility measures of successful wrestlers. Kinaithropomety. 2011;1(2011):133138. 